www.jmscr.igmpublication.org

Impact Factor 3.79

Index Copernicus Value: 5.88

ISSN (e)-2347-176x ISSN (p) 2455-0450

crossref DOI: _http://dx.doi.org/10.18535/jmscr/v4i02.72

\title{
An Open Label, Prospective Study to Evaluate the Efficacy of Misoprostol Versus Dinoprostone Gel For Induction of Labour
}

\author{
Author \\ Dr Deepanjali Lomte* \\ *Associate Professor, Dept of Pharmacology, \\ Shri Bahusaheb Hirae Govt Medical College Dhule, Maharashtra
}

\begin{abstract}
Objective: This prospective study was conducted to compare the effect, efficacy \& safety of intra-vaginal misoprostol (PGE1) \& intra-cervical dinoprostone gel (PGE 2) for induction of labour.

Methods: 60 women aged 18-35 years with single live fetus, cephalic presentation \& term pregnancy, who were admitted for induction of labour were included in this study.30 women received intrvaginal 25 microgram Misoprostol (study group) \& 30 women received $0.5 \mathrm{mg}$ of intracervical dinoprostone gel(control group). Comparison was done between the mean time taken for onset of labour, time taken for induction to delivery, mean duration of labour, requirement of Oxytocin augmentation, mode of delivery, side effects \& the neonatal outcome in either of the groups.

Results: The mean time taken for onset of labour was less in the misoprostol group than in the dinoprostone group (58.22 $\mathrm{min}$ and $1 \mathrm{hr} 55 \mathrm{~min}$ ). Similarly duration from induction to active phase (1hr $57 \mathrm{~min}$ and $4 \mathrm{hrs} 25$ min) and active phase to delivery ( $3 \mathrm{hrs} 21 \mathrm{~min}$ and $5 \mathrm{hrs} 9 \mathrm{~min}$ ) was less for misoprostol group and thus the induction to delivery interval (5 hrs $18 \mathrm{~min}$ and $9 \mathrm{hrs} 34 \mathrm{~min}$ ). Cesarean section rate was less in misoprostol group $(10 \% \mathrm{v} / \mathrm{s} 24 \%)$. Maternal side effects were minimal in either group \& the neonatal outcome was good in both the groups. The induction cost was much less in the misoprostol group.

Conclusion: Misoprostol is safe, efficacious, cheap and mother and fetus friendly drug for the induction of labour.

Keywords: Induction of labour, Misoprostol, Dinoprostone gel.
\end{abstract}

\section{Introduction}

Labor induction is a method of artificially or prematurely stimulating childbirth in a woman. ${ }^{1}$ Recently, elective inductions of labor at term have increased dramatically. Currently, two prostaglandin analogs are available for the purpose of cervical ripening-Misoprostol and Dinoprostone gel. Prostaglandin alter the extracellular ground substance of the cervix, ripen the cervix and also increases the activity of collagenase in the cervix. They also allow for an increase in intracellular calcium levels, causing contraction of myometrial muscle., ${ }^{2,3}$

Although dinoprostone gel is considered as the preferred method for labor induction, it is relatively expensive drug. The average maximum retail price is 230.50 per $0.5 \mathrm{mg}$ dose of the endocervical gel (Cerviprime, AstraZeneca Pharma). Dinoprostone gel also requires refrigeration for storage which can cause significant problems for maternity units. There is a growing interest on misoprostol, a prostaglandin 
E1 analogue for labor induction which is much cheaper and stable at room temperature. A single $100 \mu \mathrm{g}$ tablet costs 8.60, thus a low dose of $25 \mu \mathrm{g}$ dose costs approximately 2.15 Replacing dinoprostone with misoprostol would allow considerable cost savings. A large body of data exists on misoprostol for use in cervical ripening and labor induction. Vaginal application of misoprostol has been reported in over 9000 women worldwide and seems to have safety profile similar to that of dinoprostone. ${ }^{4,5}$

The initial trials have used much higher dose of drug. But the American College of Obstetricians and Gynecologists (ACOG) recommends the use of low dose of $25 \mu \mathrm{g}$ vaginal misoprostol every 3 to 6 hours. $^{6}$ The FDA revised its labeling for misoprostol in April 2002 from "contraindicated in pregnancy" to "contraindicated in pregnancy for the treatment and prevention of NSAIDinduced ulcers." ${ }^{7}$ Misoprostol (15-deoxy-16hydroxy-16 methyl-PGE1) was the first synthetic prostaglandin analogue to be made available for the treatment of peptic ulcer. Impressed by its stimulant actions on the uterus, Sanchez Ramos in1993 used it for the management of several obstetric conditions. Misoprostol is available as 25, 50, 100, 200 microgram tablets. Dinoprostone (PGE) is a synthetic preparation of naturally occurring prostaglandin E2. PGE 2 gel is available in $2.5 \mathrm{ml}$ syringe for an intracervical application of $0.5 \mathrm{mg}$ of Dinoprostone. ${ }^{8}$

\section{Material and Methods}

After the approval of Institutional Ethics committee of Dr VPMC, Nashik, total 60 antenatal women admitted for induction of labour in Civil Hospital Nashik, were included in the present study randomly. 30 women received 25 microgram intrvaginal misoprostol and another 30 women received $0.5 \mathrm{mg}$ of intracervical dinoprostone gel. Misoprostol (50microgm) was kept in the posterior fornix after making it wet. Doses were repeated in both the groups, for a misoprostol group maximum of 5 doses 4-6 hourly and for dinoprostone gel maximum of 3 doses.

\section{Inclusion criteria:}

Pregnant women aged $\geq 18$ to 35,37 completed gestational weeks with normal antenatal screening test results, amniotic fluid index of five or more, Pregnant women willing to give conform consent form for the study, Singleton pregnancy, cephalic presentation, gestation confirmed by Ultrasonography

\section{Exclusion criteria:}

Multiple pregnancies, para three or more, abnormal presentation, pregnancy < 36 weeks, estimated fetal weight more than 4000 grams, or less than 2000 grams, previous caesarean section and myomectomy. Hypersensitivity to prostaglandins, renal, hepatic or cardiovascular disease and severe asthma.

Study group: Patients who received Misoprostol for induction of labour.

Control group: Patients who received Dinoprostone gel for induction of labour.

The patient was considered in the active phase when there was cervical dilatation of at least 3-4 $\mathrm{cm}$. Women in labour were cared for, according to current obstetric practices. When they entered active phase, depending on the pattern of uterine contractility, oxytocin was used for augmentation. If women did not reach active phase within $24 \mathrm{hrs}$ of induction, caesarean section was done for failed induction. No augmentation was done when uterine contractions reached a frequency of 3 in 10 minutes. The primary outcome measure was the interval from start of induction to active phase. Success of induction was defined as entry into active phase within 24 hours of the initial administration of the drug. Other measures studied were need for oxytocin augmentation, interval from active phase to delivery, mode of delivery, need for caesarean section, and side effects. The results were represented as mean \& standard deviation \& unpaired t test was applied to know the statistical significance. Qualitative variables were expressed as percentages. Neonatal outcome was measured according to the Apgar score. 


\section{JMSCR Vol||4||Issue||02||Page 9522-9528||February}

\section{Results}

The baseline data of the study population included maternal age, gravidity and gestational age. They were comparable in the two groups. The mean gestational age was identical i.e. 37 to 42 weeks. $70 \%$ in study group and $67 \%$ in control group were in 37-40 weeks of pregnancy as seen in Table No.1.

Table No.1 Gestational age

\begin{tabular}{|l|l|l|}
\hline Gestational age (in wks) & Misoprostol & Dinoprostone \\
\hline $37-40$ & $21(70 \%)$ & $20(67 \%)$ \\
\hline $40.1-42$ & $9(30 \%)$ & $10(33 \%)$ \\
\hline
\end{tabular}

Table No.2 Indications for induction

\begin{tabular}{|l|l|l|}
\hline Indication & Misoprostol & Dinoprostone \\
\hline Post date Pregnancy & $9(30 \%)$ & $10(33.5 \%)$ \\
\hline IUGR & $9(30 \%)$ & $7(23 \%)$ \\
\hline PIH/Pre-eclampsia & $11(37 \%)$ & $11(37 \%)$ \\
\hline Eclampsia & $1(3 \%)$ & $2(6.5 \%)$ \\
\hline
\end{tabular}

Table No.3 Mean time taken for onset of labour

\begin{tabular}{|l|l|l|l|l|l|l|l|}
\hline & Misoprostol & Dinoprostone & $\begin{array}{l}\text { Mean } \\
\text { difference }\end{array}$ & S.D.(mean) & $\begin{array}{l}\text { Standard } \\
\text { error(mean) }\end{array}$ & $\mathrm{t}$ & $\mathrm{P}$ \\
\hline In all patients & $58.22 \mathrm{~min}$ & $1 \mathrm{hr} 55 \mathrm{~min}$ & $56.78 \mathrm{~min}$ & 77.85 & 11.12 & -3.3907 & 0.00069 \\
\hline In Primigravida & $59.37 \mathrm{~min}$ & 1 hour $41 \mathrm{~min}$ & & & & & \\
\hline In Multigravida & $58.25 \mathrm{~min}$ & $\begin{array}{l}1 \\
50.67 \mathrm{~min}\end{array}$ & & & & & \\
\hline
\end{tabular}

Table No. 4 Induction-delivery intervals

\begin{tabular}{|l|l|l|l|l|l|l|l|}
\hline & Misoprostol & Dinoprostone & $\begin{array}{l}\text { Mean } \\
\text { difference }\end{array}$ & $\begin{array}{l}\text { S.D. } \\
\text { (mean) }\end{array}$ & $\begin{array}{l}\text { Standard } \\
\text { error (mean) }\end{array}$ & $\mathrm{t}$ & $\mathrm{P}$ \\
\hline $\begin{array}{l}\text { Induction to } \\
\text { active phase }\end{array}$ & $1 \mathrm{hr} 57 \mathrm{~min}$ & $4 \mathrm{hrs} 25 \mathrm{~min}$ & $\begin{array}{l}28 \mathrm{~min} \\
28 \mathrm{~m}\end{array}$ & 161.76 & 24.61 & -2.71 & 0.006 \\
\hline $\begin{array}{l}\text { Active phase } \\
\text { to delivery }\end{array}$ & $3 \mathrm{hrs} 21 \mathrm{~min}$ & $5 \mathrm{hrs} 9 \mathrm{~min}$ & $1 \mathrm{hr} 48 \mathrm{~min}$ & 147.10 & 22.33 & -2.599 & 0.01275 \\
\hline $\begin{array}{l}\text { Induction to } \\
\text { delivery }\end{array}$ & $5 \mathrm{hrs} 18 \mathrm{~min}$ & $9 \mathrm{hrs} 34 \mathrm{~min}$ & $\begin{array}{l}4 \mathrm{hrs} 16 \\
\mathrm{~min}\end{array}$ & 377.60 & 54.97 & -3.8077 & 0.0004 \\
\hline
\end{tabular}

In Misoprostol group the time taken for induction

to active phase $1 \mathrm{hr} 57 \mathrm{~min} \&$ In Dinoprostone group $4 \mathrm{hrs} 25 \mathrm{~min}$. It states that in Misoprostol group time taken for induction to active phase was less which is statistically significant as $\mathrm{P}=0.006$. Similarly active phase to delivery interval ( $3 \mathrm{hrs} 21 \mathrm{~min}$ in Misoprostol group \& in Dinoprostone group $5 \mathrm{hrs} 9 \mathrm{~min}$ ), was also less and was statistically significant with $\mathrm{P}=0.01$. Overall there is less induction to delivery interval (5 hrs $18 \mathrm{~min} \mathrm{\&} 9 \mathrm{hrs} 34 \mathrm{~min}$ ) and this was statistically significant. 


\section{JMSCR Vol||4||Issue||02||Page 9522-9528||February}

Table No. 5 Mean duration of labour

\begin{tabular}{|c|c|c|c|c|c|c|c|}
\hline & Misoprostol & Dinoprostone & $\begin{array}{l}\text { Mean } \\
\text { difference }\end{array}$ & $\begin{array}{l}\text { S.D. } \\
\text { (mean) }\end{array}$ & $\begin{array}{l}\text { Standard } \\
\text { error (mean) }\end{array}$ & $\mathrm{t}$ & $\mathrm{P}$ \\
\hline $\begin{array}{l}\text { Duration of } \\
\text { labour(mean) }\end{array}$ & $4 \mathrm{hrs} 37 \mathrm{~min}$ & $7 \mathrm{hrs} 51 \mathrm{~min}$ & $3 \mathrm{hrs} 14 \mathrm{~min}$ & 212.61 & 32.5 & -2.293 & 0.01519 \\
\hline $\begin{array}{l}\text { Duration of labour } \\
\text { in Primi (mean) }\end{array}$ & $3 \mathrm{hrs} 25 \mathrm{~min}$ & $7 \mathrm{hrs} 30 \mathrm{~min}$ & 4hrs $5 \mathrm{~min}$ & 169.18 & 48.30 & -2.872 & 0.02252 \\
\hline $\begin{array}{l}\text { Duration of labour } \\
\text { in multi (mean) }\end{array}$ & $5 \mathrm{hrs} 08 \mathrm{~min}$ & $8 \mathrm{hrs} 06 \mathrm{~min}$ & $2 \mathrm{hrs} 58 \mathrm{~min}$ & 276.13 & 53.39 & -1.501 & 0.10432 \\
\hline
\end{tabular}

Mean duration of labour was much less in the misoprostol group (4 hrs $37 \mathrm{~min}$ ) than in the Dinoprostone group ( $7 \mathrm{hrs} 51 \mathrm{~min}$ ) which is significantly less $(\mathrm{P}=0.015)$ as seen in Table No. 5
Even in Primigravida patients Misoprostol resulted in shorter duration of labour (3hrs 25 min) as compared to dinoprostone gel ( $7 \mathrm{hrs} 30$ $\mathrm{min}$ ) which is statistically significant as $\mathrm{P}=0.02$

Table No. 6 Oxytocin augmentation

\begin{tabular}{|l|l|l|}
\hline & Misoprostol & Dinoprostone Gel \\
\hline & $\%$ of patients & $\%$ of patients \\
\hline Oxytocin augmentation & $10 \%$ & $10 \%$ \\
\hline
\end{tabular}

Oxytocin augmentation was required in $10 \%$ cases in both groups.

Table no.7 Mode of delivery

\begin{tabular}{|l|c|c|c|c|}
\hline $\begin{array}{l}\text { Type of delivery } \\
\% \text { of patients }\end{array}$ & \multicolumn{2}{|c|}{ No. Of patients } & \multicolumn{2}{c|}{$\%$ of patients } \\
\hline \multirow{2}{*}{ Normal vaginal } & Misoprostol & Dinoprostone & & $69 \%$ \\
\cline { 2 - 5 } & 26 & 21 & $46 \%$ & $7 \%$ \\
\hline $\begin{array}{l}\text { Instrumental } \\
\text { delivery }\end{array}$ & 1 & 2 & $4 \%$ & $24 \%$ \\
\hline Cesarean section & 3 & 7 & $10 \%$ & \\
\hline
\end{tabular}

$86 \%$ of patients in misoprostol group delivered normally as compared to $69 \%$ in dinoprostone group as seen in Table No.7 .

Thus less rate of Cesarean section seen in the misoprostol group.

Table No. 8 Indication for Cesarean section

\begin{tabular}{|l|c|c|}
\hline Indication for LSCS & Misoprostol & Dinoprostone \\
\hline Failure of Induction & 1 & 3 \\
\hline Meconium stained liquor & 2 & 1 \\
\hline Fetal Distress & - & 3 \\
\hline Total & 3 & 7 \\
\hline
\end{tabular}

Only 1 patient in study group had failure of induction whereas in control group 3 patients had failure of induction. The main indication of Cesarean section in control group was failure of induction as mentioned in Table No. 8. In the study group, Cesarean section was done mainly for meconium stained liquor which was also the second major indication for Cesarean section in the control group. 
Table No. 9 Side effects

\begin{tabular}{|l|l|l|}
\hline Side effects & \%OF PATIENTS & \%OF PATIENTS \\
\hline & Misoprostol & Dinoprostone \\
\hline Nausea, Vomiting & $8 \%$ & $4 \%$ \\
\hline Fever with chills & $16 \%$ & - \\
\hline GI symptoms & $6 \%$ & $4 \%$ \\
\hline Hyperstimulation & $8 \%$ & - \\
\hline Meconium stained liquor & $6 \%$ & $3 \%$ \\
\hline
\end{tabular}

Although maternal complications like fever with chills, Hyperstimulation (Hypersystole \& tachysystole) \& Meconium stained liquor were more in misoprostol group than in dinoprostone group as shown in Table No. 9. Significant side effect were not encountered.

Table No. 10 Neonatal outcome

\begin{tabular}{|l|l|l|}
\hline APGAR SCORE $<7$ & Misoprostole & Dinoprostone \\
\hline After $1 \mathrm{~min}$ & - & $6 \%$ \\
\hline After $5 \mathrm{~min}$ & - & $3 \%$ \\
\hline Need for NICU & - & $3 \%$ \\
\hline
\end{tabular}

Apgar score $<7$ was seen in 2 cases of dinoprostone group out of which 1 have been admitted in NICU. None of the newborn in the study group had Apgar score $<7$.

The mean overall induction cost in Misoprostol group was much less in contrast to the high overall induction cost in dinoprostone group.

\section{Discussion}

The introduction of Prostaglandins to clinical practice, particularly their local use for cervical ripening, has decreased major difficulties of labour induction. Duration between induction and delivery has been decreased dramatically by introduction of Prostaglandins. Similarly it also decreased associated complication of amnionitis and fetal infection. The baseline data of our study population including maternal age, gravidity and gestational age were comparable with similar studies $9,10,11$

In our study, indication for induction in Misoprostol group were post date pregnancy in $30 \%$ and Preeclampsia in $37 \%$ whereas in Dinoprostone group $33 \%$ and $37 \%$ respectively induced for postdated pregnancy and Preeclampsia. Thus majority of indication was due to these two conditions. Post dated pregnancy was the main indication for induction in other studies $9,10,11$

The mean time taken for onset of labour was less in misoprost group (58.22 min v/s $1 \mathrm{hr} 55 \mathrm{~min}$ ). There was no significant difference between the primigravida and the multigravida in both the groups regarding the time taken for onset of labour.

In this study the mean induction to delivery interval was less in the misoprost group (5 hrs 18 $\operatorname{min~v/s~} 9 \mathrm{hrs} 34 \mathrm{~min}$ ), which is statistically significant $(\mathrm{P}=<.001)$. Similar results were seen in study in 2003 by Agarwal et al ${ }^{12}$ where it was $12.8+/-6.4 \mathrm{hrs} \mathrm{v} / \mathrm{s} 18.53+/-8.5$ hours. In 2003 D.Garry et $\mathrm{al}^{13}$ also concluded in his study that interval from start of induction to vaginal delivery was significantly shorter in the misoprostol group. Also in another study of Murthy Bhaskar Krishnamurthy in 2006, induction delivery interval was shorter in the misoprostol group. Other reported studies ${ }^{14,15}$ also had parallel observation. Thus misoprostol reduces the mean duration of labour which reduces the duration of suffering of a patient in labour and also provides fast delivery which is required in cases of Premature rupture of membranes, eclampsia and fetal distress. 
The present study showed that Misoprostol was able to increase the vaginal deliveries compared to the control group as $86 \%$ patients delivered vaginally in study group compared to $69 \%$ in the control group. Thus Misoprostol had decrease rate of Cesarean section (10\%) compared to Dinoprostone (24\%). This was consistent with the study of Sahu Latika et $\mathrm{al}^{9}$ (8\% v/s 20\%) and also with the study of Patil Kamal et $\mathrm{al}^{10}$ and Murthy Bhaskar et al ${ }^{11}$

In the present study, in the study group, out of 3 patients who underwent cesarean section only one was for failure of induction whereas in the control group 3 out of 7 patients operated for Cesarean section due to failure of induction. Thus the main indication of Cesarean section in the dinoprostone group was failure of induction which was consistent with the study by Patil Kamal et al ${ }^{10}$ and Murthy Bhaskar et $\mathrm{al}^{11}$. In the Misoprostol group 2 out of 3 patients underwent Cesarean section due to meconium stained liquor though in the Dinoprostone group 2 patients had Cesarean section due to meconium stained liqour.

Maternal side effects were minimal in both the groups. In Misoprost group, $16 \%$ patients had fever with chills, $8 \%$ had nausea and vomiting and $6 \%$ had GI symptoms, $8 \%$ had hyper stimulation. Hypertonus was defined as one contraction with a duration of $>2$ minutes, tachysystole as $>6$ contractions in 10 minutes for two consecutive 10 minute periods ${ }^{17}$. Uterine hyperstimulation is when either of these condition (hypertonus or tachysystole) leads to a non reassuring fetal heart rate pattern ${ }^{18}$. Because of the frequency of tachysystole with vaginal administration of misoprostol, some researchers are studying oral and sublingual/buccal routes to determine if effectiveness can be maintained while decreasing the incidence of tachysystole. ${ }^{17-19}$. In 2000, G.D.Scarle \& Company notified physicians that misoprostol is not approved for labour induction or abortion. Despite this American College of Obstetricians \& Gynecologists (2000) quickly reaffirmed its recommendation for use of the drug because of proven safety $\&$ efficacy ${ }^{18}$
The neonatal outcome in both the groups was comparable. Birth weights were similar in both the groups. Apgar score < 7 at 1 min was seen in 3 cases of Dinoprostone group out of which one had to be admitted to NICU. Sahu Latika et al also had $12 \%$ newborns with Apgar $<7$ at one minute in the dinoprostone group which is consistent with our study.

The mean overall induction cost in Misoprostol group was much less in contrast to dinoprostone group. As Misoprostol does not need refrigeration, its affordability as well as its availability in the peripheral areas is more than the Dinoprostone gel which requires refrigeration.

\section{Conclusion}

Our study results revealed that, Misoprostol is better inducing agent as compared to the Dinoprostone gel because it has short induction to delivery intervals and thus short duration of labour and advantage of rapid labour as required in cases of pre-eclampsia and eclampsia.

The need of Oxytocin augmentation was same with the Misoprostol and it results in more vaginal deliveries compared to Dinoprostone. Thus Misoprostol reduces the Cesarean section rate and also has less chances of failure of induction. Although hyper stimulation and meconium stained liquor was more in Misoprost group in few patients and did not had any effect on the neonatal outcome. Misoprostol also does not need cold chain storage and is cheaper. Thus Misoprostol can be considered as safe, efficacious, cheap drug for the induction of labour.

\section{References}

1. Houghton Mifflin Company, The American Heritage Dictionary, 2006

2. Witter FR . Prostaglandin E2 preparations for preinduction cervical ripening. Clin Obstet Gynecol. 2000;43:469-74.

3. Arias F. Pharmacology of oxytocin and prostaglandins. Clin Obstet Gynecol 2000;43:455 68 .

4. Hofmeyr GJ, Gulmezoglu AM. Vaginal misoprostol for cervical ripening and 
induction of labour. The Cochrane

Database Syst Rev. 2003;CD000941. DOI:10.1002/14651858.CD000941.

5. Sanchez-Ramos L, Kaunitz AM. Misoprostol for cervical ripening and labor induction: a systematic review of the literature. Clin Obstet Gynecol. 2000; 43:475- 488.

6. ACOG committee opinion. New US Food and drug administration labeling of cytotec (misoprostol) use in pregnancy Int $\mathrm{J}$ Gynecol Obstet 2003;82:137-138.

7. American College of Obstetricians and Gynecologists. New U.S. Food and Drug Administration labeling on Cytotec (Misoprostol) use and pregnancy. Committee Opinion Washington, DC: American College of Obstetricians and Gynecologists; 1999;. 283

8. F.Gary Cunningham, Kenneth J.Leveno, Steven L.Bloom, John C., Rouse, Spong, Williams Obstetrics,2010;23:502

9. Sahu Latika,et al. Comparison of Prostaglandin E1(Misoprostol) with Prostaglandin E2(Dinoprostone) for Labor Induction. J Obstet Gynecology India 2004;54(2):139-142

10. Patil K P et al. Oral Misoprostol v/s intracervical dinoprostone for cervical ripening and labour induction. J Obstet Gynec India 2005; 55(2):128-131

11. Murthy BK et al. Misoprostol alone versus a combination of Dinoprostone and Oxytocin for induction of labour. J Obstet Gynec India 2006;56(5):413-416

12. Agarwal N, Gupta,A, Kriplani ,Bhatla NP. Six hourly vaginal misoprostol versus intracervical Dinoprostone for cervical ripening and labour induction.J Obstet and Gynecology Res 2003;29(3):147-51.

13. Garry D, Figueroa R, Kalish RB. Randomized Controlled Trial of Vaginal Misoprostol Versus Dinoprostone Vaginal Insert for labour induction Journal of
Maternal-Fetal and Neonatal Medicine 2003; 13(4):254-259

14. Calder AA, Loughney AD,Weir CJ, Barber JW. Induction of labour in nulliparous and multiparous women: a UK, multicentre, open-label sudy of intrvaginal misoprostol in comparison with dinoprostone. BJOG 2008;115(10):127988.

15. Sebiha Ozkan, Eray Caliskan, Emek Doger, Izzet Yucesoy, Semih Ozeren, Birol Vural. Comparative safety and efficacy of vaginal Misoprostol versus Dinoprostone Vaginal insert in labour induction at term: a Randomized Trial. Archives of Gynecology and Obstetrics 2009;280(1):19-24

16. Neiger R. Greaves PC. Comparison between Vaginal Misoprostol and Cervical Dinoprostone for cervical ripening and labour induction. Tenn Med. 2001; 94(1): 25-7 15. F.Gary Cunningham, Kenneth J.Leveno, Steven L.Bloom, John C., Rouse, Spong. Williams Obstetrics, 2010;23:503

17. Cheng SY, Ming H, Lee JC. Titrated oral compared with vaginal misoprostol for labor induction: A randomized controlled trial. Obstet Gynecol.2008;111:119-125.

18. Muzonzini G, Hofmeyr GJ. Buccal or sublingual misoprostol for cervical ripening and induction of labour.Cochrane Database Syst Rev. 2004;4:CD004221.

19. Colon I, Clawson K, Hunter K, Druzin ML, Taslimi MM. Prospective randomized clinical trial of inpatient cervical ripening with stepwise oral misoprostol vs vaginal misoprostol. Am J Obstet Gynecol. 2005; 192:747-752. 